\title{
Verena Brandt
}

\section{Das englische Disclosure-Verfahren}

\author{
Ein Modell für Zugang zu Information und Beweis im deutschen Zivilprozess?
}

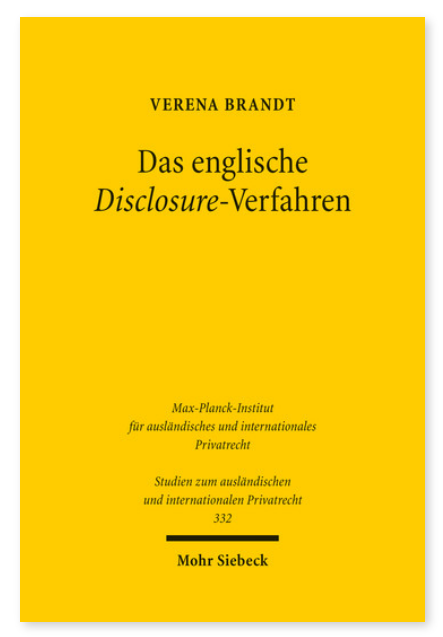

2015. XXVII, 394 Seiten. StudIPR 332

ISBN 978-3-16-152793-7

DOI 10.1628/978-3-16-152793-7

eBook PDF 89,00€

ISBN 978-3-16-152512-4

fadengeheftete Broschur $89,00 €$
Im englischen Zivilprozess bestehen im Rahmen des Disclosure -Verfahrens weitreichende Informationszugangsrechte der Parteien. Demgegenüber wird die Einführung prozessualer Aufklärungspflichten im deutschen Zivilprozess überwiegend abgelehnt. Verena Brandt vergleicht die Möglichkeiten des Zugangs zu Information und Beweis im englischen und deutschen Zivilverfahren und untersucht, inwieweit das deutsche Recht Mechanismen bereit hält, die dem Disclosure -Verfahren funktional vergleichbar sind. Sie überprüft, ob die deutsche Lösung zur Behebung unverschuldeter Informationsnot Defizite aufweist und inwieweit der Grundgedanke des englischen Disclosure -Verfahrens nutzbar gemacht werden kann. Dabei liegt der Schwerpunkt auf der Aufarbeitung des Spannungsfelds zwischen Parteiherrschaft auf der einen und Wahrheitsfindung auf der anderen Seite.

Verena Brandt Geboren 1978; Studium der Rechtswissenschaften an der Universität Regensburg; Referendariat am OLG Celle; Forschungssemester an der Universität Oxford; Studium (Master of Law) an der Universität Cambridge; Wissenschaftliche Assistentin am Max-Planck-Institut für ausländisches und internationales Privatrecht; Notarassessorin in Hamburg; 2012 Promotion; seit 2012 Notarin in Hamburg.
Jetzt bestellen:

https://mohrsiebeck.com/buch/das-englische-disclosure-verfahren-9783161527937?no_cache=1 order@mohrsiebeck.com

Telefon: +49 (0)7071-923-17

Telefax: $+49(0) 7071-51104$ 